\title{
Current and future flood risk assessment in the Danube region using an open loss modelling framework
}

\author{
Kai Schröter ${ }^{1, a}$, Max Steinhausen ${ }^{1}$, Michel Wortmann², Stefan Lüdtke ${ }^{1}$, Ben Hayes ${ }^{4}$, Martin Drews ${ }^{3}$, Fred Hattermann², \\ Heidi Kreibich ${ }^{1}$ \\ ${ }^{1}$ German Research Centre for Geoscience GFZ, Section Hydrology, Potsdam, Germany \\ 2 Potsdam Institute for Climate Impact Research, Potsdam, Germany \\ ${ }^{3}$ Technical University of Denmark DTU, Lyngby, Denmark \\ ${ }^{4}$ OASIS Imf, London, United Kingdom
}

\begin{abstract}
Climate informee planning of adaptation actions requires consistent and reliable information about future risks as well as appropropriate tools and services to support comprehensive flood risk assessment and management. The Future Danube Model is a multi-hazard and risk model suite to provide spatially consistent information on current and future extreme events and to quantify climate risks. The Future Danube Model is composed of exchangeable modules for climate input, hydrology, inundation, flood damage and risk. It is implemented within an open source platform, the OASIS Loss Modelling Framework. The application of the Future Danube Model is showcased for the assessment of current and future flood risk to residential buildings in the Danube region. Outputs from Global and Regional Climate Models for a reference period and three future climate periods are used to drive the model chain. Results show predominantly an increase in peak discharges across the Danube basin with exception for the Moldava and Tisza rivers. Future fluvial flood risk is shown to most likely increase in the future which is more pronounced for the high-end RCP84 scenario.
\end{abstract}

\section{Introduction}

Recent decades have seen a sharp increase in damaging hydro-meteorological hazards globally and further increases are expected in the future as a consequence of global change. With changing climate patterns, the seasonality, frequency and intensity of extreme hydrometeorological events is expected to exacerbate socioeconomic impacts of flooding (Hoeppe, 2016, Willner et al. 2018). Climate informed planning of adaptation actions needs consistent and reliable information about future risks and associated uncertainties, as well as appropriate tools and services to support comprehensive flood risk assessment and management.

This contribution gives an overview of the Future Danube Model (FDM), which is a multi-hazard and risk model suite for the Danube region (Hattermann et al. 2018). FDM provides climate services related to perils such as heavy precipitation, heat waves, floods and droughts under recent and future climate conditions. It provides spatially consistent information on current and future extreme events and can be used to quantify climate risks. FDM is composed of exchangeable modules for climate input including a weather generator, hydrology, inundation, risk, adaptation and visualisation. FDM is implemented within the open source OASIS Loss
Modelling Framework (LMF), which defines a standard for estimating ground-up loss and financial damage of disaster events or event scenarios as a basis for risk assessment and adaptation planning. The OASIS LMF implementation of the FDM is showcased for the current and future fluvial flood risk assessment in the Danube catchment. Stochastic inundation event sets $(10,000$ years of daily climate data) are generated for current and future climate in the Danube region using four EURO-CORDEX models as climate drivers. Long term continuous simulations of flood processes are conducted using a coupled semi distributed hydrological and a $1.5 \mathrm{D}$ hydraulic model for fluvial floods. Flood losses to residential building are estimated using a probabilistic multi-variable vulnerability model. Risk results are given as exceedance probability curves for current and future climate on different spatial aggregation levels enabling an analysis of risk hotspots.

\section{Data and models}

\subsection{The Future Danube Model}

The Future Danube Model (FDM) is a high-resolution, multi-hazard and risk model for the Danube basin. While 
FDM provides climate services for heavy precipitation, heat waves, floods and droughts under climate change (Hattermann et al. 2018), the focus of this contribution is on current and future fluvial flood risk. The model domain encompasses the entire Danube River basin covering an area of $801,000 \mathrm{~km}^{2}$ shared by 19 countries with more than 81 million inhabitants (Fig. 1).

The FDM consists of a modular chain of modelling tools including a stochastic weather generator, a hydrological and a hydrodynamic model to produce discharge and water level time-series as well as inundation depth and inundation duration maps, and a vulnerability model which translates flood intensity in combination with information about exposed assets into economic loss estimates.

The following sections give an overview of the components of the model chain, the approach to include impacts of climate change using climate projections, and the implementation into the OASIS LMF.

\subsubsection{Weather generator}

The Imperial College Weather Generator (IMAGE) is a multi-variable, multi-location weather generator which captures the point statistics and spatial-temporal autocorrelation of single and multiple variables (Sparks et al., 2017). IMAGE uses either observations, re-analysis or climate model results to capture the spatial-temporal statistics of climate variables in large regions. In the FDM application, IMAGE is used to produce 10,000 years of synthetic daily weather fields representing historical or projected future climate. IMAGE input is based on Regional Climate Model (RCM) simulations driven by Global Climate Model (GCM) scenarios, see section 2.2. Statistical characteristics of the 10,000 years are similar to those of their respective 30-year baseline periods from GCM-RCM simulations.
Extreme events of higher recurrence interval are sampled and generated spatially and temporally consistent over the entire Danube River basin.

The 10,000 years of synthetic weather are used to drive continuous long-term simulations of hydrological and hydraulic/inundation processes and to generate stochastic event sets for coherent flood risk assessment (e.g. Falter et. al 2015). Weather simulations from four different EURO-CORDEX GCM-RCM combinations represent the ensemble spread, i.e. the uncertainty of climate projections.

\subsubsection{Hydrological model}

The eco-hydrological Soil and Water Integrated Model (SWIM) (Krysanova et al., 2005) has been developed to investigate impacts of changes in climate, land use, and water management (reservoirs and irrigation) on catchment hydrology (including floods and droughts) and vegetation processes (e.g. crop yields) at the regional scale. SWIM has a record of successful applications in flood related studies (Huang et al., 2013; Hattermann et al., 2014, 2016). SWIM uses a semi-distributed spatial discretisation approach and generally operates at a daily time step, but is able to simulate runoff related processes (e.g. infiltration) and discharge processes (e.g. river routing) with sub-daily time steps. In the FDM, the hydrological module produces daily discharge time-series based on weather simulations (IMAGE) for climate projections. These time-series are used as input for the next component of the model chain, i.e. the hydraulic model. For FDM, the SWIM model was set up for the entire Danube River basin with a spatially detailed resolution represented by 13,473 sub-basins and 190,000 hydrological response units defined as unique combinations of sub-basins, land-use, soil types and elevation zones. This high-resolution model set-up enables

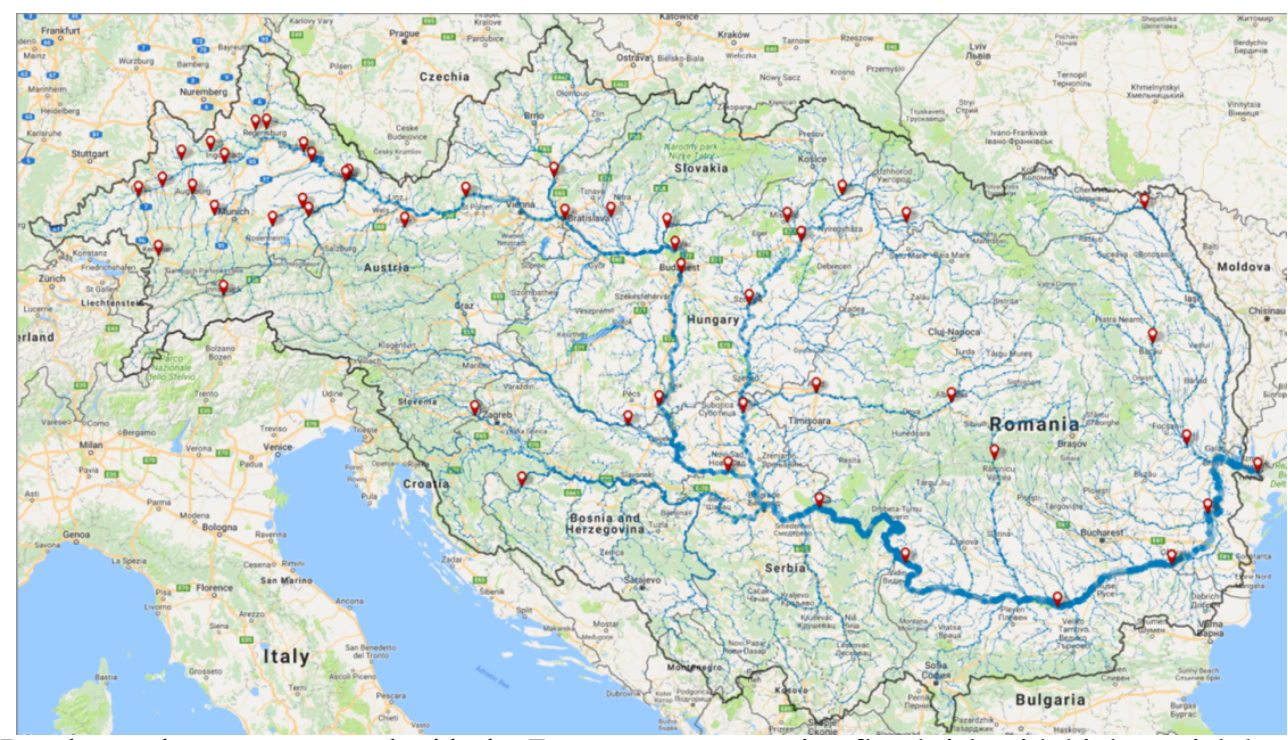

Figure 1. Danube catchment represented with the Future to examine flood risk with high spatial detail (Fig 1). Danube model (FDM) with main rivers and gauging stations, source layers OSM 2019. 
The model is calibrated at 44 gauging stations across the basin using a multi-objective, genetic optimisation algorithm. The RMSE of observed and simulated annual maximum discharge recurrence levels (of a fitted Gumbel distribution) as well as the Nash-Sutcliff Efficiency and absolute bias in water balance are used as objective functions. Model performances are correlated with precipitation densities (good-very good in the upper basin, moderate in the Carpathian part region

\subsubsection{Hydraulic model}

The daily discharge time-series produced by SWIM are used to drive the semi-distributed hydrodynamic model CamaFlood (Yamazaki et al., 2011; 2014). CamaFlood uses a local inertia form as a difference approximation of the shallow water equations to route SWIM subbasin runoff. Water levels are derived using simplifying assumptions of river width-depth relations and conveyance capacity to represent cross section and floodplain geometry. River width is inferred from Open Street Map riverbank outlines. The depth is adjusted according to the peak discharge of the protection level provided by the FLOPROS database (Scussolini et al., 2016), or to the mean annual maximum discharge when flood protection is not considered or unknown. CamaFlood outputs are daily water levels at each river reach which is used in combination with terrain height to construct daily or aggregated 7-day maximum inundation depth and inundation duration flood intensity footprints. The event set of flood footprints includes ca. 350'000 events per simulation period and scenario discretised into $10 \mathrm{~cm}$ intervals.

\subsubsection{Vulnerability model}

The economic impact of floods in FDM can be assessed in terms of direct damage to residential and commercial building structures, and, given the modular set-up, can be readily extended to include additional sectors. In this contribution, FDM uses the probabilistic multi-variable vulnerability model for the private sector BN-FLEMOps (Wageneaar et. al 2018; Lüdtke et al. 2019) to estimate direct damage to residential buildings. BN-FLEMOps implements a Bayesian Network approach to infer the conditional joint probability of relative building loss according to a graphical network structure (cf. Wagenaar et al. 2018). This network structure is derived from empirical post-event survey data collected after flood events in Germany (2002 - 2013) and expert knowledge. The model output are probability distributions for relative building loss conditional on flood intensity (inundation depth, inundation duration, return period of the event) as well as residential building characteristics (building area, flood experience of the household, precautionary measures). The model has been validated using official loss records for historic events across Europe (Lüdtke et al. 2019). Depending on the scope and the availability of input data, BN-FLEMOps can be applied both for individual buildings or aggregated land use units. In this study, BN-FLEMOps is implemented on the basis of land- use units. Accordingly, flood losses are estimated for socalled response units. These response units are spatial polygons which are the outcome of an intersection process of inundation depth and duration maps provided by the hydraulic model component with other input variables characterising vulnerability including flood experience, building area and residential asset values (Lüdtke et al. 2019).

\subsubsection{Input data}

The components of the FDM model chain are based on various data sources which need to be consistently available for the entire Danube region. Table 1 lists the variables, sources and references of the basic data sets used for FDM in this study.

\begin{tabular}{|c|c|c|}
\hline Variable & Source & Reference \\
\hline $\begin{array}{l}\text { Climate } \\
\text { (daily) }\end{array}$ & $\begin{array}{c}\text { E-OBS, WATCH } \\
\text { (radiation only); } \\
\text { EURO-CORDEX, } \\
0.25^{\circ}\end{array}$ & $\begin{array}{c}\text { Haylock et al. } \\
\text { (2008), } \\
\text { Weedon et al. (201 } \\
\text { 1), } \\
\text { Jacob et al. (2014) }\end{array}$ \\
\hline $\begin{array}{l}\text { Land Use } \\
\text { Land Cover }\end{array}$ & $\begin{array}{l}\text { CORINEv18 2012, } \\
\text { 100m; GLIMS } \\
\text { (glaciers); } \\
\text { OpenStreetMap } \\
\text { (lakes, residential } \\
\text { and industrial } \\
\text { areas) }\end{array}$ & $\begin{array}{l}\text { EEA (2016b), } \\
\text { OSM (2019), }\end{array}$ \\
\hline Soils & HWSD, $1 \mathrm{~km}$ & FAO et al. (2011) \\
\hline Elevation & $\begin{array}{c}\text { EU-DEM v1.1, } \\
25 \mathrm{~m}\end{array}$ & EEA (2016a) \\
\hline River network & OpenStreetMap & OSM (2019) \\
\hline $\begin{array}{l}\text { Lakes, } \\
\text { reservoirs }\end{array}$ & OpenStreetMap & OSM (2019) \\
\hline $\begin{array}{c}\text { Residential } \\
\text { building areas }\end{array}$ & OpenStreetMap & OSM (2019) \\
\hline $\begin{array}{c}\text { Flood } \\
\text { experience in } \\
\text { Europe } \\
\end{array}$ & $\begin{array}{l}\text { Dartmouth Flood } \\
\text { Observatory }\end{array}$ & Brakenridge, 2018) \\
\hline $\begin{array}{c}\text { Residential } \\
\text { building assets }\end{array}$ & $\begin{array}{c}\text { Eurostat } \\
\text { CORINEv18 } 2012\end{array}$ & $\begin{array}{c}\text { Eurostat 2018, } \\
\text { EEA, 2016b, } \\
\text { Steinhausen et al. } \\
2020\end{array}$ \\
\hline
\end{tabular}

Table 1. FDM input data sources and references.

Climate data comprises of an observation datasets (EOBS, Haylock et al., 2008; and WATCH, Weedon et al. 2011) as well as climate model output (EURO-CORDEX, Jacob et al., 2014). These data sets are available from the Copernicus Climate Data Store. Further, the hydrological model SWIM uses information about soil properties from the harmonized world soil database (HWSD, FAO et al. 2011) as well as land use land cover characteristics (CORINE, EEA, 2016b). Terrain height information for sub-basin delineation and description of floodplain topography is provided by a $25 \mathrm{~m}$ DEM from the European Union (EEA, 2016a). Information about river networks, lakes and reservoirs as well as residential building footprints is taken from OpenStreetMap (OSM 2019). For 
the vulnerability model BN-FLEMOps the input datasets comprise a flood experience layer, residential building footprint areas, and an asset map which provides unit area values of residential building in EURO per square meter based on reconstruction cost and GDP per capita for NUTS-3 administrative regions or countries. These layers are available from GFZ data repository (Steinhausen et al. 2020). The model set-up of FDM has been validated on the level of individual model components by comparing simulation outcomes with observed data (Hattermann et al. 2018; Lüdtke et al. 2019).

\subsection{Climate projections}

The climate scenarios are based on Representative Concentration Pathways (RCPs, van Vuuren et al., 2011, Meinshausen et al. 2011) from the latest climate scenario generation of the International Panel for Climate Change. The scenarios RCP4.5 and RCP 8.5 have been selected to represent possible climate projections. RCP4.5 constitutes a moderate scenario with temperature increases around 2.5 ${ }^{\circ} \mathrm{C}$ and RCP8.5 a high-end scenario with temperature increases around $3.5^{\circ} \mathrm{C}$ until the end of this century in the Danube area (Jacob et al., 2014). Bias corrections of RCM simulations have been done using present-day E-OBS weather data with a resolution of 0.25 degrees.

Using the IMAGE weather generator, 30 years of weather simulations from four different EURO-CORDEX GCM-RCM combinations (Table 2), re-presenting the reference (1970-1999) and three future climate periods (2006-2035, 2020-2049 and 2070-2099), are used to generate 10,000 years of synthetic weather for each of the these periods and the two RCP scenarios. In total, 280,000 years of synthetic weather data were generated by the IMAGE weather generator.

\begin{tabular}{|c|c|c|}
\hline $\begin{array}{c}\text { Climate model } \\
\text { combinations }\end{array}$ & \multicolumn{1}{c|}{$\begin{array}{c}\text { Climate } \\
\text { Periods }\end{array}$} & Scenarios \\
\hline ICHEC-KNMI & $\begin{array}{c}\text { Reference } \\
(1970-1999)\end{array}$ & \\
& $\begin{array}{c}\text { Current } \\
\text { ICHEC-SMHI }\end{array}$ & \multirow{2}{*}{ RCP-4.5 } \\
& $\begin{array}{c}2006-2035) \\
\text { Near future } \\
\text { MOHC-SMHI }\end{array}$ & \\
& $\begin{array}{c}2020-2049) \\
\text { MPI-MPI }\end{array}$ & Far future \\
& RCP-8.5 \\
\hline
\end{tabular}

Table 2. Global-regional climate model combinations (abbreviations relate to the modelling institutes: Irish centre for high end computing (ICHEC), Dutch Meteorological Institute (KNMI), Swedish Meteorological Institute (SMHI), Met Office Hadley Centre (MOHC), Max Planck Institute for Meteorology

(MPI), simulated climate periods and RCP scenarios..

\subsection{OASIS LMF}

OASIS LMF is an open source platform for developing, deploying and executing catastrophe models (www.oasislmf.org). It includes a web based user interface and an API for integration with other systems. Basically, the LMF devises a way of dividing up the elements of catastrophe loss modelling into "plug and play" components. These comprise of hazard and vulnerability models along with exposure and possibly insurance policy terms. These components are linked to the LMF kernel which performs the calculations for the defined inputs. OASIS LMF is a framework in that it provides general structures within which specific modelling tasks can be implemented and efficiently solved using the computation kernel. Prescribed file formats to provide input information to the kernel and the calculation approaches implemented in the kernel build the standard underlying the LMF. Within the FDM implementation the flood footprints produced by the hydraulic model and the probability distributions for relative building loss are used as input to the OASIS LMF. Residential exposure is derived from residential asset maps with spatially variable vulnerability characteristics. With these inputs OASIS LMF produces a set of risk assessment reports that provide ground-up loss to residential buildings for event scenarios.

\section{Results}

Future changes in flood hazard in the Danube basin generally point to increases in peak discharges across the basin with west-east increasing gradient in line with changes in 3 and 7-day precipitation intensities of the IMAGE output. Decreases are only simulated in the Czech Republic (Moldava River) and in parts of the Tisza headwaters. Changes in peak discharges increase with RCP scenarios, e.g. at Budapest (Danube River), the 100year median peak discharge of the reference period is equalled or exceeded ca. every 50-80 (30-60) years under RCP-4.8 (8.5), Fig. 2.

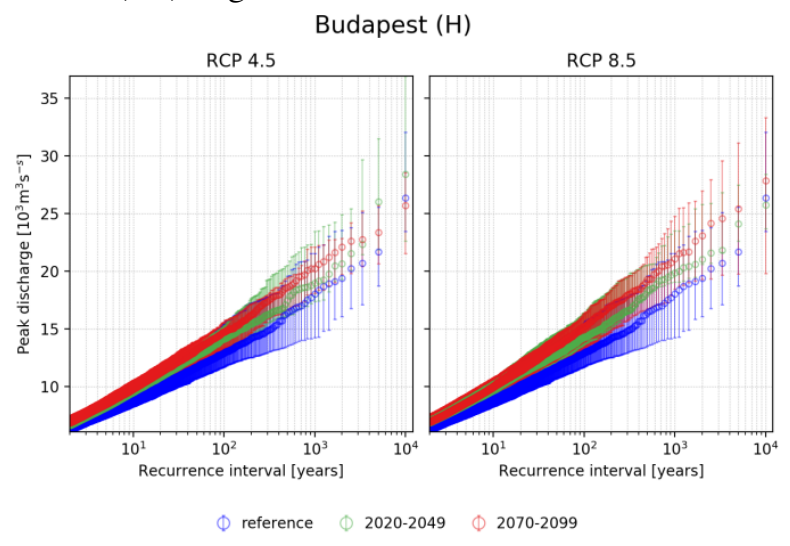

Figure 2. Recurrence intervals of flood peak discharges at the gauge Budapest for two RCPs within the reference and future climate periods.

The evaluation of flood risk to residential buildings indicates an increase of flood losses across the whole range of return periods. While for the moderate RCP45 scenario the increase with time, i.e. from current climate to near and far future is small, the RCP85 scenario indicates a continuous increase of flood losses throughout the $21^{\text {st }}$ century with a more pronounced raise of losses caused by low-probability, i.e. high return period floods (Fig. 3). 


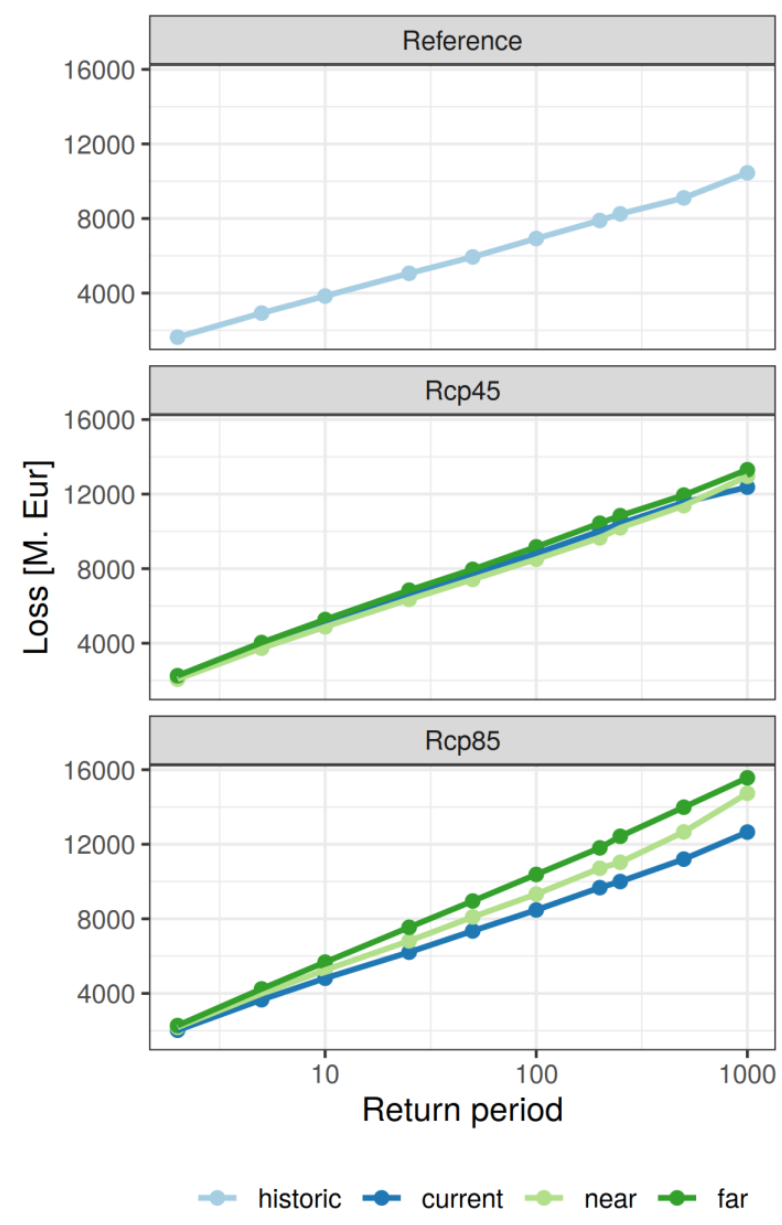

Figure 3. Aggregated Exceedance Probability curves for fluvial flood risk of residential buildings in the Danube catchment for the reference and future climate periods and two RCPs.

These numbers represent preliminary insights to future flood risk in the Danube region. Additional analysis need to be undertaken, in particular to gain a better understanding of the spatial distribution of flood risk throughout the whole Danube catchment.

\section{Conclusions}

This contribution gives an overview of the Future Danube Model and its implementation to the open source loss modelling framework OASIS LMF. The results presented give a glimpse to the capabilities of the Future Danube Model for the consistent assessment of climate risks in large catchments. Using a chain of validated models for current climate, projections of four biascorrected EURO-CORDEX GCM-RCM combinations and two scenarios were used to show that the fluvial flood risk in the Danube region is likely to increase in the future which is more pronounced for the high-end RCP84 scenario. The outputs of the Future Danube Model may inform (re-)insurers and flood risk managers about the potential future risk including higher order return periods. Given the comprehensive and consistent approach for integrating climate change scenarios in risk assessment and simulating its impacts in the entire Danube River basin, the Future Danube Model is a valuable tool for trans-boundary flood risk assessment and management. With regard to the EU floods directive, the Future Danube Models demonstrates how future climate risk can be taken into consideration. The process based model components allow investigating and quantifying effects of flood risk mitigation measures.

The implementation according to the OASIS LMF standard eases the uptake of the tool by other users. Further, the modular concept makes it possible to exchange individual model components with alternative modelling tools and approaches. The open source OASIS LMF provides transparent, state of the art probabilistic modelling approaches and enables to efficiently process large data sets.

\section{Acknowledgements}

This research has received funding from the European Union's Horizon 2020 research and innovation programme under grant agreement No 730381

\section{References}

1. Brakenridge, G. R. (2018). Global active archive of large flood events. Retrieved from http://floodobservatory.colorado.edu/Archives/index. $\underline{\mathrm{html}}$

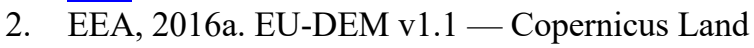
Monitoring Service.

3. EEA, 2016b, CLC 2018 - Copernicus Land Monitoring Service.

4. Eurostat. (2018). Gross domestic product (GDP) at current market prices by NUTS 3 regions. Retrieved 30 November 2018, from http://appsso.eurostat.ec.europa.eu/nui/show.do?data set=nama 10r 3gdp\&lang=en

5. Falter, D., Schröter, K., Dung, N.V., Vorogushyn, S., Kreibich, H., Hundecha, Y., Apel, H., Merz, B., 2015. Spatially coherent flood risk assessment based on long-term continuous simulation with a coupled model chain. Journal of Hydrology. 524, 182-193

6. FAO, IIASA, ISRIC, ISSCAS, JRC, 2011. The Harmonized World Soil Database (Database No. 1.2). FAO and IIASA, Rome.

7. Hattermann, F.F., Huang, S., Burghoff, O., Hoffmann, P., Kundzewicz, Z.W., 2016. Brief Communication: An update of the article "Modelling flood damages under climate change conditions \&ndash; a case study for Germany". Natural Hazards and Earth System Sciences 16, 1617-1622.

8. Hattermann, F.F., Huang, S., Burghoff, O., Willems, W., Österle, H., Büchner, M., Kundzewicz, Z., 2014. Modelling flood damages under climate change conditions - a case study for Germany. Nat. Hazards Earth Syst. Sci. 14, 3151-3168.

9. Hattermann, F.F., Wortmann, M., Liersch, S., Toumi, R., Sparks, N., Genillard, C., Schröter, K., Steinhausen, M., Gyalai-Korpos, M., Máté, K., Hayes, B., del Rocío Rivas López, M., Rácz, T., Nielsen, M.R., Kaspersen, P.S., Drews, M., 2018. Simulation of flood hazard and risk in the Danube 
basin with the Future Danube Model. Climate Services 12, 14-26.

10. Haylock, M.R., Hofstra, N., Tank, A.M.G.K., Klok, E.J., Jones, P.D., New, M., 2008. A European daily high-resolution gridded data set of surface temperature and precipitation for 1950-2006. Journal of Geophysical Research: Atmospheres 113.

11. Hoeppe, P., 2016. Trends in weather related disasters - Consequences for insurers and society. Weather and Climate Extremes, Observed and Projected (Longer-term) Changes in Weather and Climate Extremes 11, 70-79.

12. Huang, S., Hattermann, F.F., Krysanova, V., Bronstert, A., 2013. Projections of climate change impacts on river flood conditions in Germany by combining three different RCMs with a regional ecohydrological model. Climatic Change 116, 631-663.

13. Jacob, D., Petersen, J., Eggert, B., Alias, A., Christensen, O.B., Bouwer, L.M., Braun, A., Colette, A., Déqué, M., Georgievski, G., Georgopoulou, E., Gobiet, A., Menut, L., Nikulin, G., Haensler, A., Hempelmann, N., Jones, C., Keuler, K., Kovats, S., Kröner, N., Kotlarski, S., Kriegsmann, A., Martin, E., van Meijgaard, E., Moseley, C., Pfeifer, S., Preuschmann, S., Radermacher, C., Radtke, K., Rechid, D., Rounsevell, M., Samuelsson, P., Somot, S., Soussana, J.-F., Teichmann, C., Valentini, R., Vautard, R., Weber, B., Yiou, P., 2014. EUROCORDEX: new high-resolution climate change projections for European impact research. Reg Environ Change 14, 563-578.

14. Krysanova, V., Hattermann, F., Wechsung, F., 2005. Development of the ecohydrological model SWIM for regional impact studies and vulnerability assessment. Hydrological Processes 19, 763-783.

15. Lüdtke, S., Schröter, K., Steinhausen, M., Weise, L., Figueiredo, R., Kreibich, H., 2019. A Consistent Approach for Probabilistic Residential Flood Loss Modeling in Europe. Water Resources Research 55, 10616-10635.

16. Meinshausen, M., Smith, S.J., Calvin, K., Daniel, J.S., Kainuma, M.L.T., Lamarque, J.-F., Matsumoto, K., Montzka, S.A., Raper, S.C.B., Riahi, K., Thomson, A., Velders, G.J.M., van Vuuren, D.P.P., 2011. The RCP greenhouse gas concentrations and their extensions from 1765 to 2300. Climatic Change 109, 213.

17. OSM, 2019. OpenStreetMap [WWW Document]. OpenStreetMap. URL https://www.openstreetmap.org/ (accessed 6.18.19).

18. Scussolini, P., Aerts, J.C.J.H., Jongman, B., Bouwer, L.M., Winsemius, H.C., de Moel, H., Ward, P.J., 2016. FLOPROS: an evolving global database of flood protection standards. Nat. Hazards Earth Syst. Sci. 16, 1049-1061.

19. Sparks, N.J., Hardwick, S.R., Schmid, M., Toumi, R., 2017. IMAGE: a multivariate multi-site stochastic weather generator for European weather and climate. Stoch. Environ. Res. Risk Assess. 1-14.

20. Steinhausen, M.; Schröter, K.; Lüdtke, S.; Drews, M. (2020): European exposure data for BN-FLEMO models. V. 1.0. GFZ Data Services. http://doi.org/10.5880/GFZ.4.4.2020.001

21. van Vuuren, D.P., Edmonds, J., Kainuma, M., Riahi, K., Thomson, A., Hibbard, K., Hurtt, G.C., Kram, T., Krey, V., Lamarque, J.-F., Masui, T., Meinshausen, M., Nakicenovic, N., Smith, S.J., Rose, S.K., 2011. The representative concentration pathways: an overview. Climatic Change 109, 1.

22. Wagenaar, D., Lüdtke, S., Schröter, K., Bouwer, L.M., Kreibich, H., 2018. Regional and Temporal Transferability of Multivariable Flood Damage Models. Water Resources Research. 54 (5), 36883703

23. Weedon, G.P., Gomes, S., Viterbo, P., Shuttleworth, W.J., Blyth, E., Österle, H., Adam, J.C., Bellouin, N., Boucher, O., Best, M., 2011. Creation of the WATCH Forcing Data and Its Use to Assess Global and Regional Reference Crop Evaporation over Land during the Twentieth Century. J. Hydrometeor. 12, 823-848.

24. Willner, S.N., Levermann, A., Zhao, F., Frieler, K., 2018. Adaptation required to preserve future highend river flood risk at present levels. Science Advances 4, eaao1914.

25. Yamazaki, D., Kanae, S., Kim, H., Oki, T., 2011. A physically based description of floodplain inundation dynamics in a global river routing model. Water Resources Research 47.

26. Yamazaki, D., Sato, T., Kanae, S., Hirabayashi, Y., Bates, P.D., 2014. Regional flood dynamics in a bifurcating mega delta simulated in a global river model. Geophysical Research Letters 41, 31273135 . 